\title{
Responses of Medullary Lateral Line Units of the Goldfish, Carassius auratus, to Amplitude-Modulated Sinusoidal Wave Stimuli
}

\author{
Ramadan Ali, Joachim Mogdans, and Horst Bleckmann \\ Institute of Zoology, University of Bonn, Poppelsdorfer Schloss, 53115 Bonn, Germany \\ Correspondence should be addressed to Joachim Mogdans, mogdans@uni-bonn.de \\ Received 13 November 2009; Revised 11 March 2010; Accepted 8 April 2010 \\ Academic Editor: Randy J. Nelson
}

Copyright ( $) 2010$ Ramadan Ali et al. This is an open access article distributed under the Creative Commons Attribution License, which permits unrestricted use, distribution, and reproduction in any medium, provided the original work is properly cited.

\begin{abstract}
This paper describes the responses of brainstem lateral line units in goldfish, Carassius auratus, to constant-amplitude and to amplitude-modulated sinusoidal water motions. If stimulated with constant-amplitude sinusoidal water motions, units responded with phasic (50\%) or with sustained $(50 \%)$ increases in dicharge rate. Based on isodisplacement curves, units preferred low $(33 \mathrm{~Hz}$, $12.5 \%)$, mid $(50 \mathrm{~Hz}, 10 \%$ and $100 \mathrm{~Hz}, 30 \%)$ or high $(200 \mathrm{~Hz}, 47.5 \%)$ frequencies. In most units, responses were weakly phase locked to the carrier frequency. However, at a carrier frequency of $50 \mathrm{~Hz}$ or $100 \mathrm{~Hz}$, a substantial proportion of the units exhibited strong phase locking. If stimulated with amplitude-modulated water motions, units responded with a burst of discharge to each modulation cycle, that is, units phase locked to the amplitude modulation frequency. Response properties of brainstem units were in many respects comparable to those of midbrain units, suggesting that they emerge first in the lateral line brainstem.
\end{abstract}

\section{Introduction}

Fishes and aquatic amphibians use their lateral line system to detect weak water motions such as those caused by predators, prey, or conspecifics [1-3]. To study the physiology and behavioural relevance of the mechanosensory lateral line, many researchers stimulated this sensory system with water motions caused by a stationary sphere that vibrated with constant amplitude and frequency (e.g., [4-6]). However, pure sine wave stimuli are rare in nature. Instead, natural hydrodynamic stimuli are often broadband and show amplitude fluctuation [7]. Therefore it is conceivable that the lateral line system of fishes has evolved to cope with more complex hydrodynamic stimuli. Keeping this in mind it is not surprising that a large number of central lateral line units does not respond to pure sine waves but readily respond to the water motions generated by a moving object [8]. Those that do respond to pure sine wave stimuli often respond only at stimulus onset or end [8-10].
Primary lateral line nerve fibers are very sensitive to and exhibit strong phase locking in response to singlefrequency constant-amplitude water motions (e.g., $[5,11-$ 16]). If the stimulus is amplitude-modulated (AM), the temporal discharge patterns of primary lateral line afferents in addition are modulated according to the amplitude modulation frequency (AMF) [15]. The first site for lateral line information processing in the fish brain is the medial octavolateralis nucleus (MON) of the medulla $[17,18]$. This nucleus receives input from the lateral line periphery via the lateral line nerves [19]. The responses of MON units to pure sine wave stimuli have been investigated in previous studies (e.g., $[8,20,21])$ demonstrating that compared to primary afferent nerve fibres, MON units exhibit lower spontaneous and evoked rates of activity, show greater degrees of adaptation, are less sensitive to pure sine wave stimuli, and can have much broader and more complex receptive fields. However, it has never been tested how MON-units respond to amplitude-modulated water motions. The output neurons of the MON project to the midbrain torus semicircularis 
[22]. Plachta et al. [10] have described the responses of toral units to constant-amplitude and amplitude-modulated sine wave stimuli and found that, unlike primary lateral line afferents, many toral lateral line units do not phase lock to the carrier frequency (CF) of a pure tone stimulus, but they do phase lock to the AMF. This indicates that information processing has occurred between the lateral line periphery and the central nervous system but does not show whether the response properties of toral units are generated first in the torus semicircularis or already at the level of the MON.

The present study was carried out to describe the responses of MON units of goldfish, Carassius auratus, to constant-amplitude and amplitude-modulated water motions. The stimuli applied had different CFs and modulation depths (MD). The results show that MON units exhibit responses that are in many respects comparable to those recorded in the torus semicircularis [10], suggesting that these properties emerge first in the lateral line brainstem.

\section{Materials and Methods}

Goldfish, Carassius auratus $(n=41)$ ranging in length from $8 \mathrm{~cm}$ to $15 \mathrm{~cm}$, were used for the experiments. Animals were acquired from commercial dealers and were maintained in 250 litre aquaria at ambient temperature $\left(20-23^{\circ} \mathrm{C}\right)$ on a daily 10-14 h light-dark cycle.

2.1. Animal Preparation. Prior to surgery, fish were anaesthetized by placing them in ice water and/or in water containing 0.05\% MS 222. Pancuronium bromide (Organon Teknika, 0.1-0.32 $\mu \mathrm{g} \mathrm{g}^{-1}$ ) was administered by an intramuscular injection to immobilize the fish. During surgery fish received artificial respiration with fresh water through a tube inserted into the fish's mouth. Water was consistently rinsed over the back and flanks of the fish to prevent drying of those parts of the skin that were not covered by water. To get access to the brain, a small area of skin on top of the head was carefully removed. With a small electric drill an opening (about $4 \mathrm{~mm} \times 4 \mathrm{~mm}$ ) was made in the skull above the MON. Excess fatty tissue and fluids were aspirated. After surgery fish were transferred to an experimental tank $(40 \mathrm{~cm}$ $\times 48 \mathrm{~cm} \times 25 \mathrm{~cm}$ ) filled with tap water (temperature $20^{\circ} \mathrm{C}$ ). The tank rested on a pneumatic table (Micro-g, TMC) to isolate the experimental setup from background vibrations. In the tank, fish were positioned on a Styrofoam support with the body tipped up by about $15^{\circ}$ such that the dorsal part of the head and thus the opening in the skull was just above the water surface. In addition, one end of a small Plexiglas rod was glued to the fish's forehead while the other end of the rod was attached to a micromanipulator. This kept the animal, in particular the head, in a fixed position allowing for stable electrophysiological recordings. Fish received artificial respiration with aerated freshwater that was pumped at a rate of $70-200 \mathrm{ml} \mathrm{min}^{-1}$ over the gills through polyethylene tubing inserted into the fish's mouth. To prevent the exposed brain tissue from drying, a physiological salt solution [23] was repeatedly applied from a plastic pipette to the opening in the skull.
2.2. Stimulation. Hydrodynamic stimuli were generated with a sphere (diameter $8 \mathrm{~mm}$ ) that was attached to a stainless steel rod (length $10 \mathrm{~cm}$, diameter $3 \mathrm{~mm}$ ). The rod was mounted to a minishaker (Ling Dynamic Systems, model V101) that rested on a sliding bar assembly allowing for manual adjustment of sphere location along the side of the fish. All stimulation equipment was mounted on a table separate from the one holding the experimental tank thus preventing transmission of unwanted vibrations to the animal via the ground and experimental tank. The electronic signals that were delivered to the mini-shaker were generated with a computer (Apple Power Macintosh 7300) using the software SuperScope II (GWI). Signals were read out of a 14-bit DA-converter at a conversion rate of $16 \mathrm{kHz}(\mathrm{GWI}$, Instrunet 100B), low-pass filtered at $2000 \mathrm{~Hz}$ (custombuilt filter) and power amplified (Ling Dynamic Systems, model PA25E) before being passed on to the mini-shaker. Carrier frequencies (CFs) of the stimuli were 33, 50, 100 and $200 \mathrm{~Hz}$, amplitude-modulation frequencies (AMF) were $4 \mathrm{~Hz}$ or $10 \mathrm{~Hz}$, and amplitude modulation depth (AMD) varied between 0 and $96 \%$. To create AM stimuli, a sinusoidal CF was multiplied with a rectified sinusoidal modulator frequency, that is, the resulting AMF had a periodicity of twice the modulator frequency. Different peak-to-peak ( $\mathrm{p}$ p) displacement amplitudes and AMDs were obtained by changing the voltages of the computer-generated signals. Stimulus duration was $1000 \mathrm{~ms}$ with rise and fall times of $100 \mathrm{~ms}$. To avoid boundary layer effects [24] on the surface of the fish and on the surface of the sphere, the distance between the fish and the sphere was $\geq 5 \mathrm{~mm}$.

2.3. Stimulus Calibration. To calibrate the displacement amplitude of the vibrating sphere, its motion was monitored with a calibrated capacitive displacement sensor (Type 4810, Probe Model 2804, LOT-Oriel) for the different CFs and AMFs applied in the physiological experiments and for different displacement amplitudes $(50-300 \mu \mathrm{m})$. The output voltage of the sensor was directly proportional to the displacement amplitude of the sphere. The time waveforms of the sensor output were digitized (GWI, Instrunet and SuperScope II, sampling rate $10 \mathrm{kHz}$ ) and stored on a computer (Apple Power Macintosh 7300). The results from these measurements indicated that the time waveforms of the output of the displacement sensor faithfully reproduced the electronic signal delivered to the mini-shaker that was driving the sphere. During electrophysiological experiments the amplitude of the electronic signal was adjusted such that the vibration amplitude of the sphere was $160 \mu \mathrm{m}$.

The actual p-p displacement amplitudes of the hydrodynamic stimuli at the skin of the fish were calculated from the following equations [25]. In the case of a vibrating sphere, the displacement at a given point in space is the vector sum of the angular and radial displacements, expressed as

$$
d_{r}=D\left(\frac{A^{3}}{r^{3}}\right) \cos \Phi, \quad d_{F}=D\left(\frac{A^{3}}{r^{3}}\right)(\sin \Phi) \frac{1}{2}
$$

where $d=$ displacement at distance $r, D=$ displacement of the source, $A=$ radius of the source, $r=$ distance to the 
center of the source, and $\Phi$ the angle between the direction of sphere vibration and the point in question. The underlying assumption is that the displacement $D$ of the sphere is small relative to the distance $r$ such that $r$ and $D$ can be considered as constants throughout the motion of the sphere. This assumption was fullfilled since in our experiments $D$ was $160 \mu \mathrm{m}$ and $r$ was $10 \mathrm{~mm}$, that is, $r$ was about 63 times greater than $D_{\max }$.

2.4. Identification of Lateral Line Units. Single unit and few unit recordings were made in the medial octavolateralis nucleus (MON) with glass micropipettes filled with an indium alloy [26] (impedance $\leq 1 \mathrm{M} \Omega$ ) or with $3 \mathrm{~mol} / \mathrm{l} \mathrm{KCl}$ (impedance 50-90 M $\Omega$ ). If indium electrodes were used, the tip of the electrode was plated with gold and platinum. Electrodes were mounted to a holder and placed over the surface of the medulla ipsilateral to the side of stimulation under visual control trough surgery binoculars (Leica M651). They were advanced dorsoventrally through the brain in small steps using a manual micromanipulator. The electrode first passed through a layer of descending parallel fibres that was readily identified by its background hash activity. The electrode was advanced further until brisk and high-amplitude action potential could be distinguished from the background noise. Most likely these action potentials arose from the large somata of the crest cells lying just below the parallel fibres [18].

With this approach, the probability of recording from resident lateral line neurons is substantially greater than recording from brainstem units of other modalities, in particular auditory units. Auditory nuclei are located medial and ventral to the MON [27] and will not be recorded if the electrode is not placed to deep and too far medial. Nevertheless, we conducted simple physiological tests at each recording site to define the modality of the recorded units (lateral line, auditory, and vestibular). Auditory units responded strongly to airborne sound (speech, clapping hands) and vestibular units responded to minute vibrations produced by tapping the edge of the experimental tank with a pipette. If auditory or vestibular units were encountered, they were not further investigated. Lateral line units responded exclusively to water motions but not to airborne sound and vibrations. The physiological tests were verified by lesion reconstructions that showed that all lesioned recording sites were located in the MON.

2.5. Data Acquisition and Analysis. Neuronal activity was amplified (DAM 80, WPI), band pass filtered $(300-3000 \mathrm{~Hz})$, displayed on an oscilloscope (HM 205-3), digitized (GWI, Instrunet 100B) and recorded with a computer (Apple Power Macintosh 7300). Units were isolated from background noise using software discriminators (GWI, SuperScope II) that delivered a time stamp for each action potential above a selected level or within a window of amplitudes. Spike waveforms were inspected visually to discriminate singleunit recordings from few unit clusters. If not otherwise stated this report presents data from single unit recordings.

For analysis, the times of occurrence of action potentials relative to stimulus onset were calculated from the time stamps. To characterize the temporal patterns of neuronal responses, raster diagrams and peri-stimulus-time histograms (PSTHs, bin width $50 \mathrm{~ms}$ or $100 \mathrm{~ms}$ ) were computed across ten stimulus repetitions. To determine ongoing activity, the number of spikes during a one second period prior to stimulus onset was determined across all stimulus presentations and expressed in spikes per second. To quantify responses to dipole stimulation, we calculated the total number of spikes that occurred during stimulation, and peak spike rates, that is, the number of spikes in the greatest bin in the PSTH. To determine the degree of phaselocking, period histograms were generated by calculating the phase relation between individual spikes and the CF or the AMF. Degree of phase coupling (vector strength or synchronization coefficient $R$ ) [28] was calculated with a selfwritten macro using Igor Pro (Wavemetrics Inc.). An R-value of 1 represents perfect synchronization, i.e. all spikes occur at the same phase of a stimulus cycle, whereas an $R$-value of 0 means that spikes are distributed evenly over the entire wave cycle. The Rayleigh test was applied to determine whether or not measures of synchronization were statistically significant [29]. This test yields a $Z$ value, $Z=R^{2} * N$, where $N=$ total number of spikes. $Z$ values above 4.6 indicate a probability of 0.01 or less that spikes are randomly distributed during a stimulus cycle.

2.6. Histological Verification of Recording Sites. In 15 fish, an electrolytic lesion was made in the final electrode penetration at a physiologically characterized recording site by passing a small current for 2-5 minutes through the electrode. Fish were sacrificed with an overdose MS 222 and perfused through the heart with a physiological salt solution followed by a fixative ( $2 \%$ glutaraldehyde/ $2 \%$ paraformaldehyde in phosphate buffer). Brains were removed, postfixed and cut in $50 \mu \mathrm{m}$ sections in a transverse plane parallel to the electrode tracks. Sections were stained with cresyl violet and analyzed under a microscope. In these sections, 11 lesions were recovered of which 8 were located within or just dorsal to the crest cell layer (Figure 1), and three were located in the ventral neuropil of the MON.

\section{Results}

\subsection{Responses to Constant-Amplitude Sine Wave Stimuli}

3.1.1. Response Patterns. A total of 55 single MON units were recorded in 18 goldfish. Average ongoing activity was 14.4 \pm 13.2 spikes/s (mean \pm S.D., range 0.1-53.9, median 10.0). The majority of the units $(n=37,67 \%)$ had ongoing rates between 2 and 20 spikes/s. Five units (9\%) had ongoing rates below 2 spikes/s and the remaining 13 units $(24 \%)$ had ongoing rates greater than 20 spikes/s.

Responses to constant-amplitude and amplitudemodulated sine wave stimuli were obtained from 46 units. When stimulated with a constant-amplitude stimulus, 50\% of the units $(n=23)$ responded with phasic discharges, that is, they fired a few action potentials at stimulus onset (Figure 2, left column). The other $50 \%$ of the units ( $n=$ 23) exhibited sustained responses, that is, discharge rates 


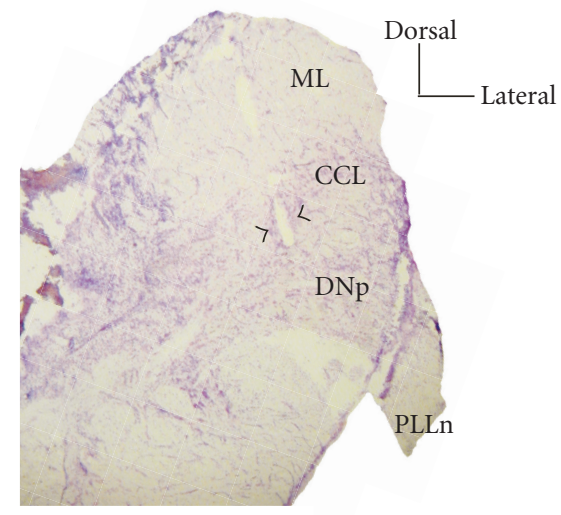

Figure 1: Reconstruction of a recording site in the medulla. The figure shows a cresyl-violet stained section through the dorsal half of the right brainstem of a goldfish. The course of an electrode penetration can be tracked from the brain surface through the molecular layer into the crest cell layer. At the endpoint of the penetration a current was applied to lesion the tissue at a physiologically characterized recording site (arrowheads). Note that the electrode was angled by about $20^{\circ}$ for easier access to the brain surface, resulting in an angular orientation of the electrode track with respect to the dorsal surface of the brain. Abbreviations: ML molecular layer, CCL crest cell layer, DNp deep neuropil, PLLn posterior lateral line nerve.

were increased for as long as the stimulus was on (Figure 2, right column). A summary plot showing the normalized discharge rate per bin (binwidth $100 \mathrm{~ms}$ ) as function of time after stimulus onset is given in Figure 3. If the CF was $33 \mathrm{~Hz}$ and $50 \mathrm{~Hz}, 40 \%$ to $50 \%$ of all units reached the maximum discharge rate within $100-200 \mathrm{~ms}$ after stimulus onset. If the CF was $100 \mathrm{~Hz}$ or $200 \mathrm{~Hz}, 72 \%$ to $74 \%$ of the cells had strongest responses within 100-200 ms after stimulus onset.

3.1.2. Frequency Response. The frequency characteristics of MON units were determined by measuring iso-displacement curves. Units were defined as having a preference for a particular frequency if spike rates in response to other frequencies were at best $60 \%$ of those in response to the preferred frequency. Under these conditions, 30 units were identified as being frequency-selective. Five units (12.5\%) preferred $33 \mathrm{~Hz}$, four units (10\%) had a preference for $50 \mathrm{~Hz}$, twelve units (30\%) for $100 \mathrm{~Hz}$ and nine units (47.5\%) for $200 \mathrm{~Hz}$ (Figure 4). Thus, across the range of frequencies applied, MON units exhibited low-pass, band-pass and highpass characteristics.

3.1.3. Phase Coupling to Constant-Amplitude Sine-Wave Stimuli. Strength of phase-coupling of MON units is shown in Figure 5 in which the Rayleigh statistic $(Z)$ is plotted versus the coefficient of synchronization $(R)$. In each graph, units with no phase locking $(Z<4.6)$ are represented by symbols below the horizontal line. Weakly phase locking units $(R<$ 0.5 ) are represented by symbols in the upper left quadrant, strongly phase locking units $(R \geq 0.5)$ are represented by symbols in the upper right quadrant. At the CF $50 \mathrm{~Hz}, 66 \%$ of all units showed phase locking $(Z \geq 4.6)$ and $38 \%$ of these units even showed strong phase locking. At the CF $100 \mathrm{~Hz}$, $98 \%$ of all units showed phase locking $(Z \geq 4.6)$ and $50 \%$ of these units even showed strong phase locking. At 33 and $200 \mathrm{~Hz}, \mathrm{MON}$ units barely phase locked to the stimulus.

\subsection{Responses to Amplitude-Modulated Sine Wave Stimuli}

3.2.1. Response Patterns. Responses of MON units evoked by amplitude-modulated $(4 \mathrm{~Hz}$ and $10 \mathrm{~Hz})$ constant frequency water motions differed from those evoked by the unmodulated carrier. Units responded with a burst of discharge to each modulation cycle (Figures 6 and 7). Thus, responses of MON units that were phasic when the stimulus was not amplitude-modulated were now sustained for the duration of the AM stimulus.

3.2.2. Phase Coupling to Amplitude-Modulated Stimuli. Most MON units significantly phase locked to the CFs 50 and $100 \mathrm{~Hz}$ but not to the CFs 33 and $200 \mathrm{~Hz}$. However, most units significantly phase locked to the AMF $4 \mathrm{~Hz}$ and $10 \mathrm{~Hz}$, provided the $\mathrm{CF}$ was $\geq 50 \mathrm{~Hz}(Z \geq 4.6)$. These findings are represented by the data in Figure 5 (middle and right columns) for all MON units tested with AM stimuli. At $4 \mathrm{~Hz}$ and $10 \mathrm{~Hz} \mathrm{AM}$, respectively, $2.5 \%$ and $0 \%(\mathrm{CF} 33 \mathrm{~Hz}$ ), $26 \%$ and $14 \%(\mathrm{CF} 50 \mathrm{~Hz}), 44 \%$ and $21 \%(\mathrm{CF} 100 \mathrm{~Hz})$ and $44 \%$ and $56 \%$ (CF $200 \mathrm{~Hz}$ ) of the units had $R$-values greater than 0.5 . These units are represented by symbols in the upper right quadrants. Most of the remaining units at least weakly phase locked to the AMF, exhibiting $R$-values smaller than 0.5 . These units are represented by symbols in the upper left quadrants.

3.2.3. Response as Function of Modulation Depth. Responses to AM stimuli also depended on modulation depth (Figure 8). When modulation depth was maximal (96\%), units responded to each modulation cycle with about the same number of spikes, that is, responses were sustained for the duration of the stimulus. When modulation depth was less than maximal, units tended to discharge with a decreasing number of spikes to increasing numbers of AM cycles. When modulation depth was $24 \%$ or smaller, discharge patterns resembled those in responses to unmodulated CFs, that is, units responded with an on-response to the first AM cycle but responded only weakly to successive AM cycles.

\section{Discussion}

4.1. Origin of Brainstem Responses. The first site of lateral line information processing in the fish brain is the medullary medial octavolateralis nucleus (MON). This nucleus receives ascending inputs from primary afferent fibers of the anterior and posterior lateral line nerves [17-19, 30]. In addition, it receives descending inputs through a parallel fibre system originating from the lateral eminentia granularis of the caudal cerebellum [30] and from efferent fibres originating in the nucleus preeminentialis [22]. In physiological studies, the verification of recordings from lateral line units is difficult due to the presence of units of other sensory 

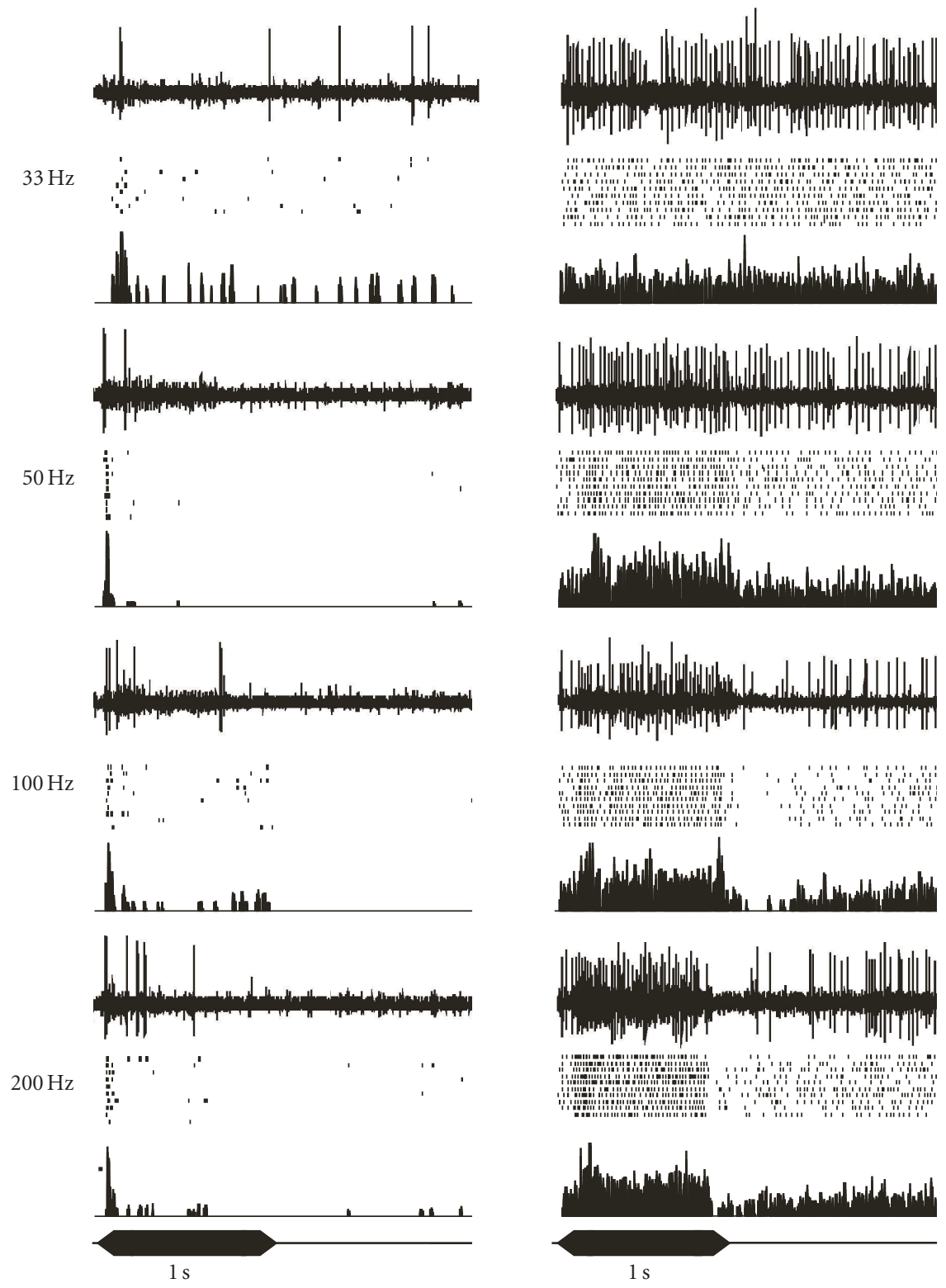

Figure 2: Examples of MON unit responses to a stationary sphere vibrating with 33, 50, 100 or $200 \mathrm{~Hz}$. Each graph shows an original recording, a dot display illustrating spike activity to ten stimulus presentations and a peri-stimulus time (PST) histogram (bin width 10 ms). The envelope of the stimulus traces are shown at the bottom. Peak-peak displacement amplitude of the sphere was $160 \mu \mathrm{m}$. Left; example of a phasic response. Right: example of a sustained response.

modalities that may respond to the applied hydrodynamic stimuli. In the part of the brain that we were recording from, the only sensory input other than from the lateral line comes from the otolith organs of the inner ear [22]. However, auditory units are located deeper in the brainstem than lateral line units $[22,27]$ and are readily identified physiologically since they respond to sound and/or vibration. Based on these criteria that we applied on each recording (see Material and Methods), we are confident that the data presented here were obtained exclusively from lateral line units.

Another problem of medullary recordings is whether they were made from output neurons, interneurons or passing fibres. This distinction can only be made satisfactorily if a unit is recorded intracellularly, filled and stained with an intracellular dye and recovered in histological sections of the brain. Intracellular recordings, however, are mechanically unstable and therefore units cannot be held long enough to allow for an extended stimulus protocol like the one used in our study. We used anatomical and physiological criteria to distinguish responses of MON neurons from the responses of primary afferents terminating in the MON. We targeted the so-called crest cell layer in the MON, an area that contains mainly output neurons [18]. To do so, the electrode was, as in previous studies (e.g., $[8,19]$ ), advanced through the parallel fibres that are overlying the crest cell layer. These 

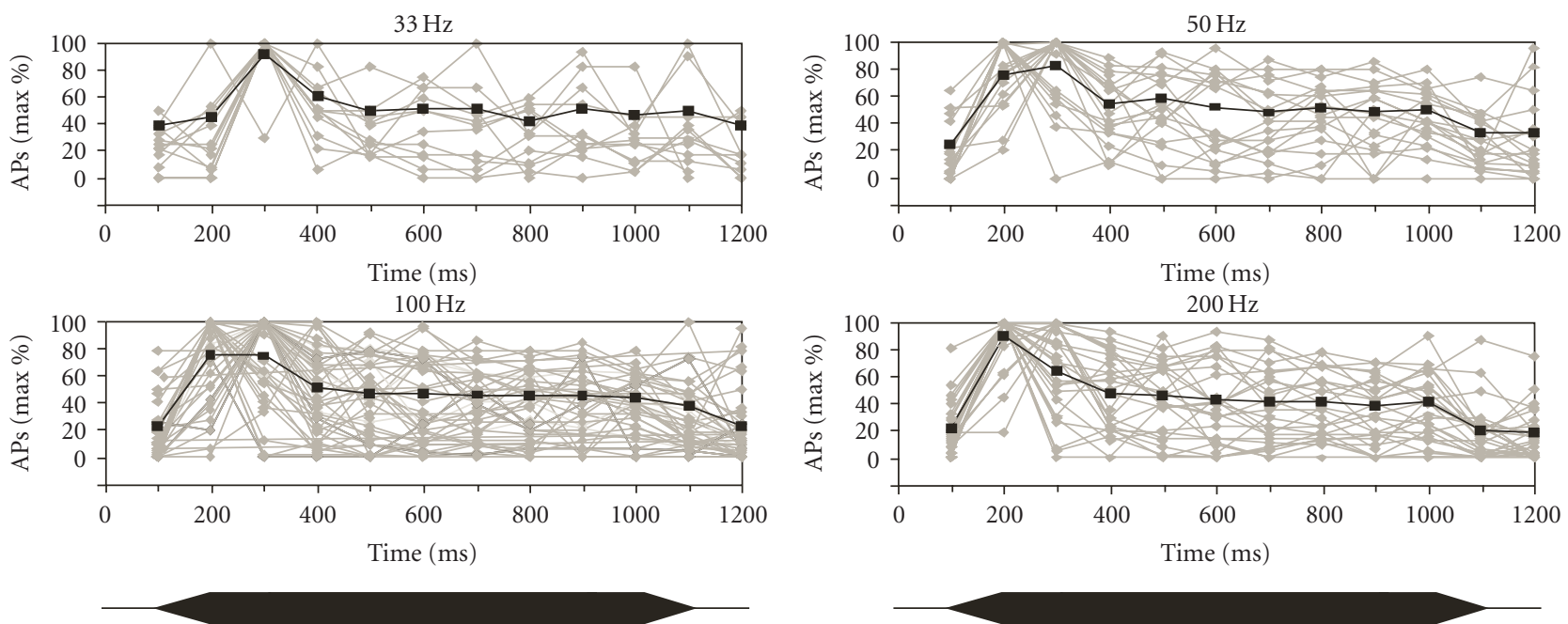

FIgURE 3: Temporal patterns of the responses to constant-amplitude sine wave stimuli. For this graph, spike activity of each unit was normalized to the greatest number of spikes elicited during a $100 \mathrm{~ms}$ time bin at any of the four frequencies presented. The envelope of the stimulus trace is shown at the bottom. Peak-peak displacement was $160 \mu \mathrm{m}$.

fibres are identified in neurophysiological experiments by their background hash activity. We advanced the electrode through these fibres until brisk and high-amplitude action potential could be distinguished from the background noise. Most likely these action potentials were arising from the somata of cells located in this area. Lesion reconstructions verified that most of the recording sites were located in or close to the crest cell layer. However, we cannot exclude the possibility that some of the recordings were from local interneurons in the crest cell layer or in the overlying layer of parallel fibres [18].

A physiological criterion to distinguish recordings from neurons from those of afferent nerve fibres is the temporal discharge pattern. In most recordings, temporal discharge patterns were quite different from those reported for primary afferent fibres (see below) making it unlikely that they were obtained from afferent nerve fibres terminating in the MON. However, some units were encountered that exhibited primary-like properties, that is, high spontaneous rates, sustained responses to a $\mathrm{CF}$ stimulus and strong phase-locking. In addition, few lesions were located in the deep neuropil of the MON. Thus, it is possible that those recordings that were located deep in the MON and exhibited primary-like properties were indeed made from ascending afferent fibres in the MON.

\subsection{Peripheral and Central Unit Responses to AM Stimuli.} Previous studies have shown that primary afferent nerve fibers are spontaneously active with average rates ranging from about 20 spikes/s [31], to 30 and 35 spikes/s [32-34]. Afferent fibres show a sustained and phase locked response to constant-amplitude sinusoidal water motions $[5,12]$, [15, Table 1]. Peripheral frequency tuning is rather broad, that is, primary lateral line afferents that respond only to a narrow frequency range have not been found (see [35], but see [36]). When stimulated with AM sine wave stimuli, primary lateral line afferents phase lock to both, the CF and the AMF.
Even if MD is as high as $96 \%$, discharge rates of primary afferents are reduced at most by $24 \%$ with respect to the discharge rate elicited by the unmodulated stimulus $[15$, Table 1]. Thus, although the synchronization coefficients to the AMFs are substantially smaller than those to the $\mathrm{CF}$, the discharges of primary lateral line afferents clearly reproduce both, the envelope and the $\mathrm{CF}$ of the stimulus [15].

The ongoing activities of units in the MON are lower than those of primary afferent nerve fibers. Different authors report numbers ranging from 5.5 spikes /s [21] to 11 spikes/s [37], 15 spikes/s [38], and up to 27 spikes/s [39]. The data from the present study (average of 14.4 spikes/s) fit the published data. If stimulated with sinusoidal water motions, MON units may respond with excitation or suppression of ongoing activity (e.g., $[20,40]$ ), and many MON units may phase-lock to the CF of a pure tone stimulus (e.g., $[21,40]$ ). The present data show that, on average, phase-locking of MON-units is weaker than phase-locking of primary lateral line afferents, a finding that is in agreement with previous studies (e.g., [15], [21, Table 1]). The responses of many MON-units were purely phasic. However, when stimulated with amplitude-modulated tones, these units exhibited a burst of discharge to each cycle of the modulation frequency. In contrast to afferent fibres, discharge patterns of MON units resembled those in responses to unmodulated $\mathrm{CFs}$ when MD was $24 \%$ or smaller. With further increasing MD, units responded more and more to the AMF. In consequence, the overall discharge rate of MON units was greater in response to an AM stimulus than in response to a pure tone stimulus of the same duration and amplitude. In addition, at a CF of $200 \mathrm{~Hz}$, phase-locking of MON units to the AMFs $4 \mathrm{~Hz}$ and $10 \mathrm{~Hz}$ was greater than to the pure tone stimulus. Finally, when stimulated with pure tones of different frequency, MON units exhibited preferences for distinct frequencies, that is, MON units exhibited low-pass, band-pass and high-pass characteristics (Table 1). 

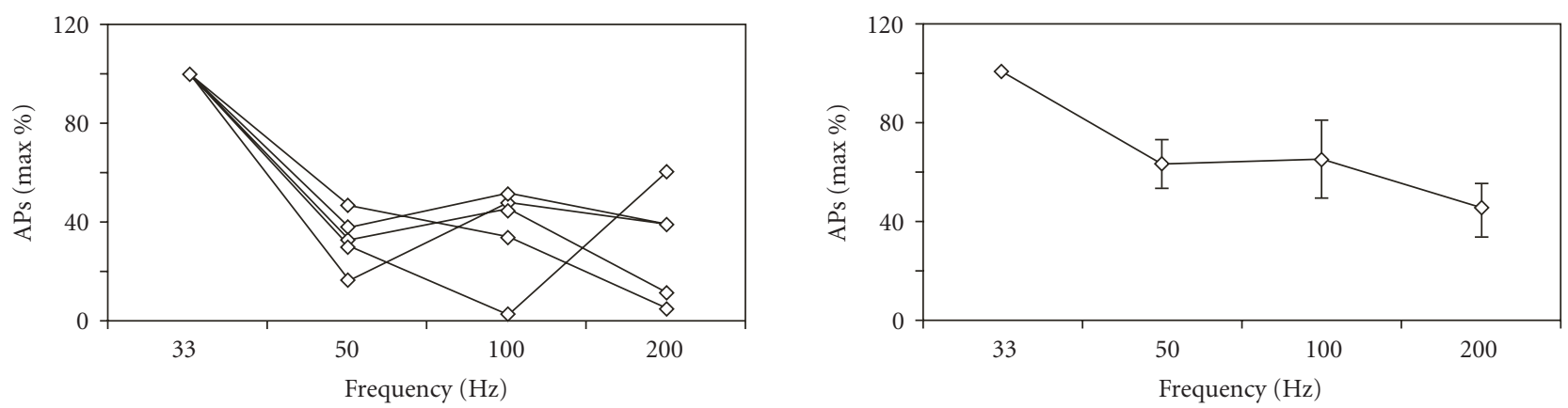

(a)
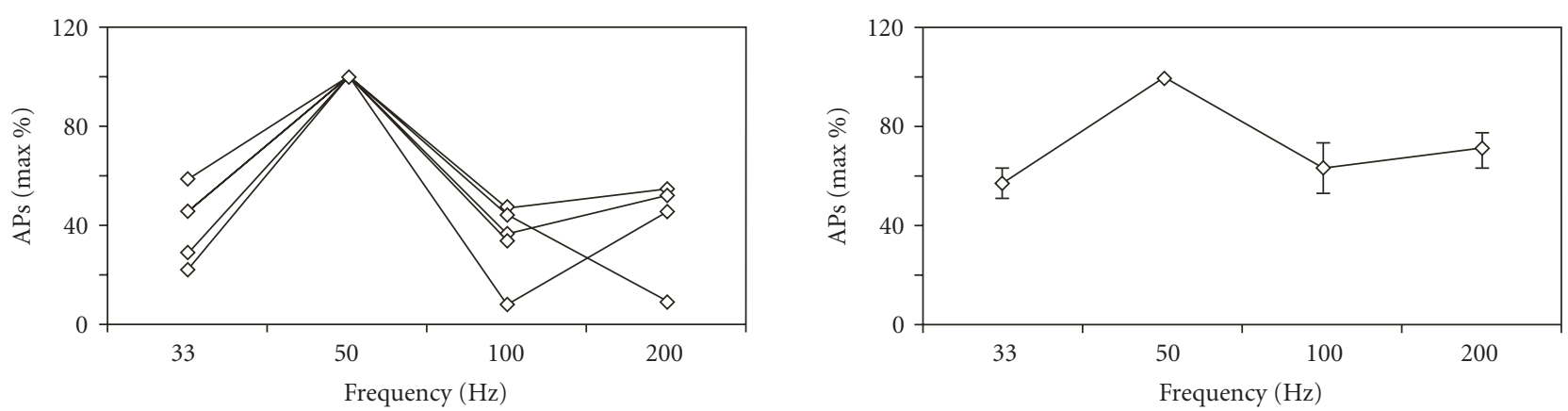

(b)
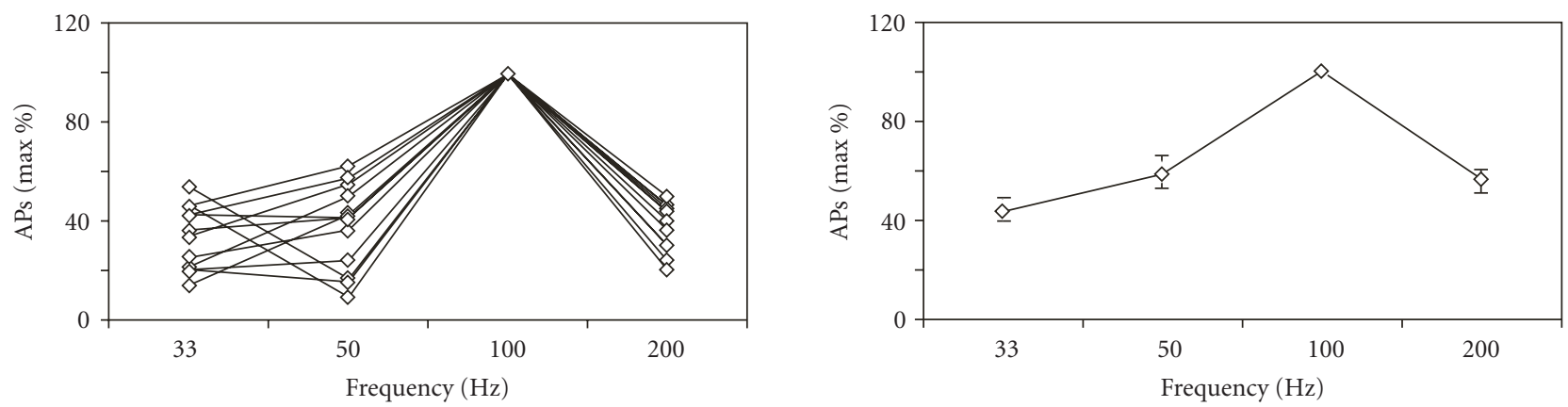

(c)
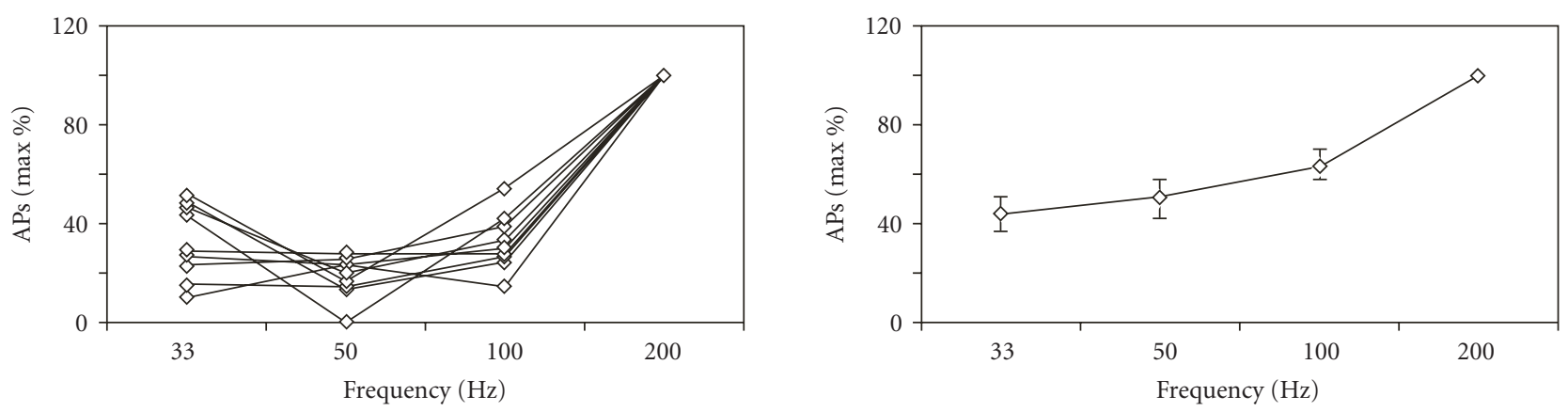

(d)

FIGURE 4: Frequency response functions of MON units. For this graph, spike activity of each unit was normalized to the greatest numbers of spikes elicited during the entire time of stimulation at any of the four frequencies presented. Left, response functions of individual units. Right, average \pm one standard deviation of the functions shown on the left. Units exhibited low-pass (a), band-pass (b, c) or high-pass characteristics (d). 


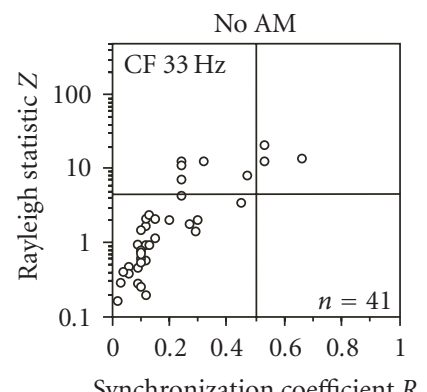

Synchronization coefficient $R$

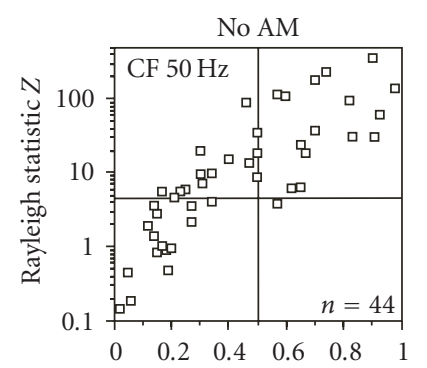

Synchronization coefficient $R$
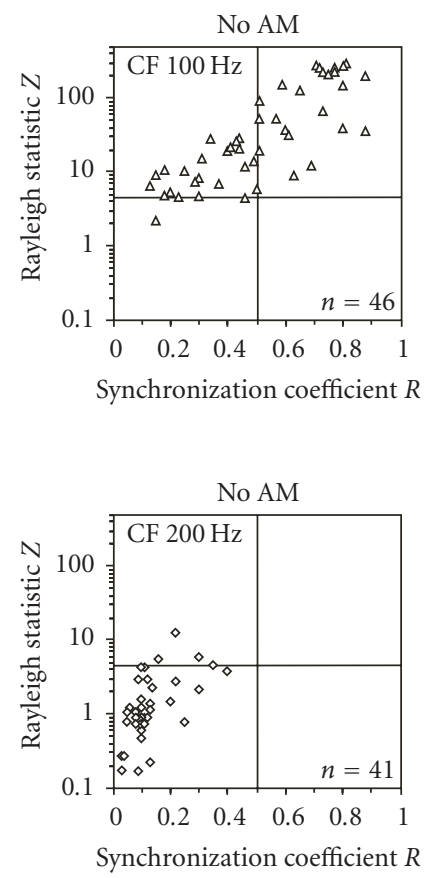

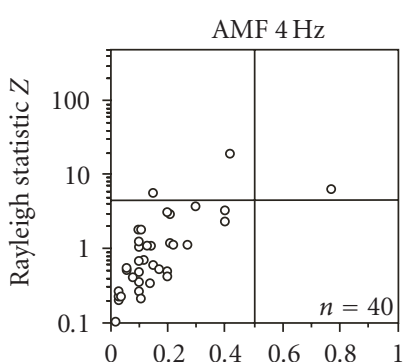

Synchronization coefficient $R$

(a)

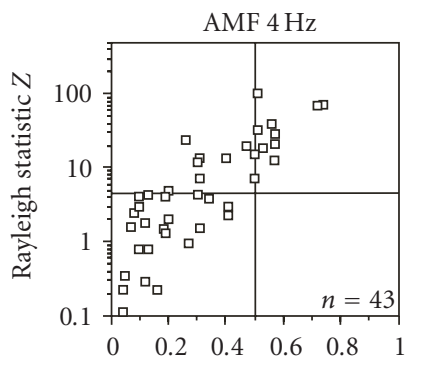

Synchronization coefficient $R$

(b)

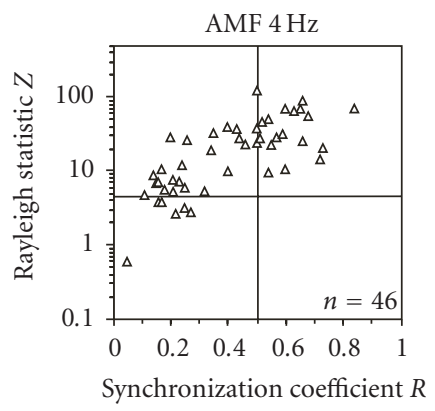

(c)

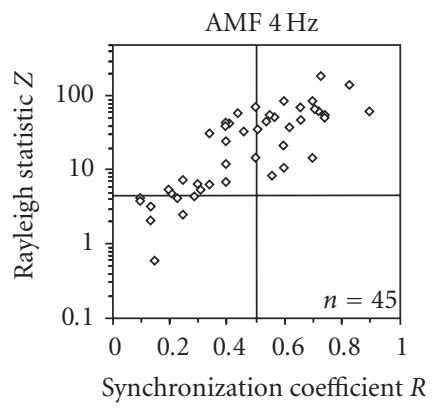

(d)

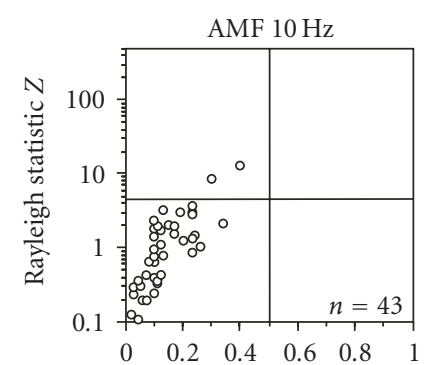

Synchronization coefficient $R$

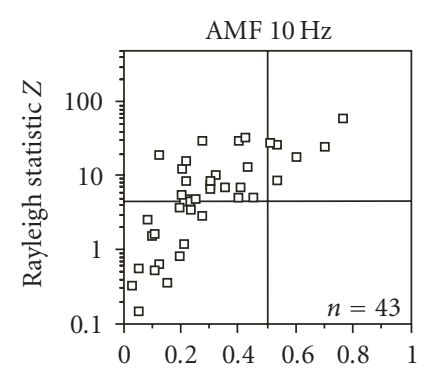

Synchronization coefficient $R$
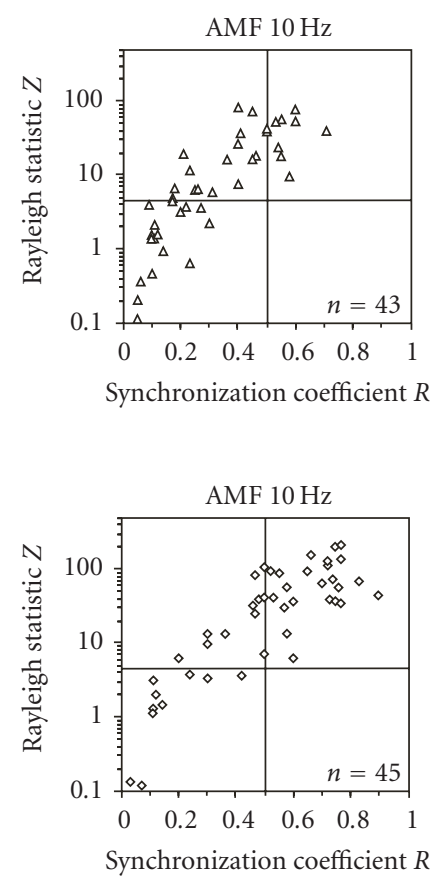

FIGURE 5: Phase coupling of MON units to constant-amplitude and to amplitude-modulated sine wave stimuli. $Z$ values obtained from the Rayleigh test are plotted versus coefficients of synchronization $(R)$ with respect to the CF (left column) or with respect to the AMF (middle and right columns: $4 \mathrm{~Hz}$ and $10 \mathrm{~Hz}$, resp.). Horizontal lines, critical value of the Rayleigh test $(Z=4.6)$. Vertical line, $R=0.5$. See text for more detail.

In contrast to afferent nerve fibers and MON units, toral lateral line units show nearly no ongoing activity (average numbers typically <1 spike/s) [10, 41-43]. Even toral lateral line units that show a sustained response to a pure tone stimulus do not phase-lock to the CF of the stimulus [10, Table 1]. However, if the stimulus amplitude is modulated sinusoidally, toral lateral line units-like MON units-discharge to each modulation cycle. In consequence, the overall discharge rate of a toral lateral line unit is greater in response to an AM stimulus than in response to a pure 

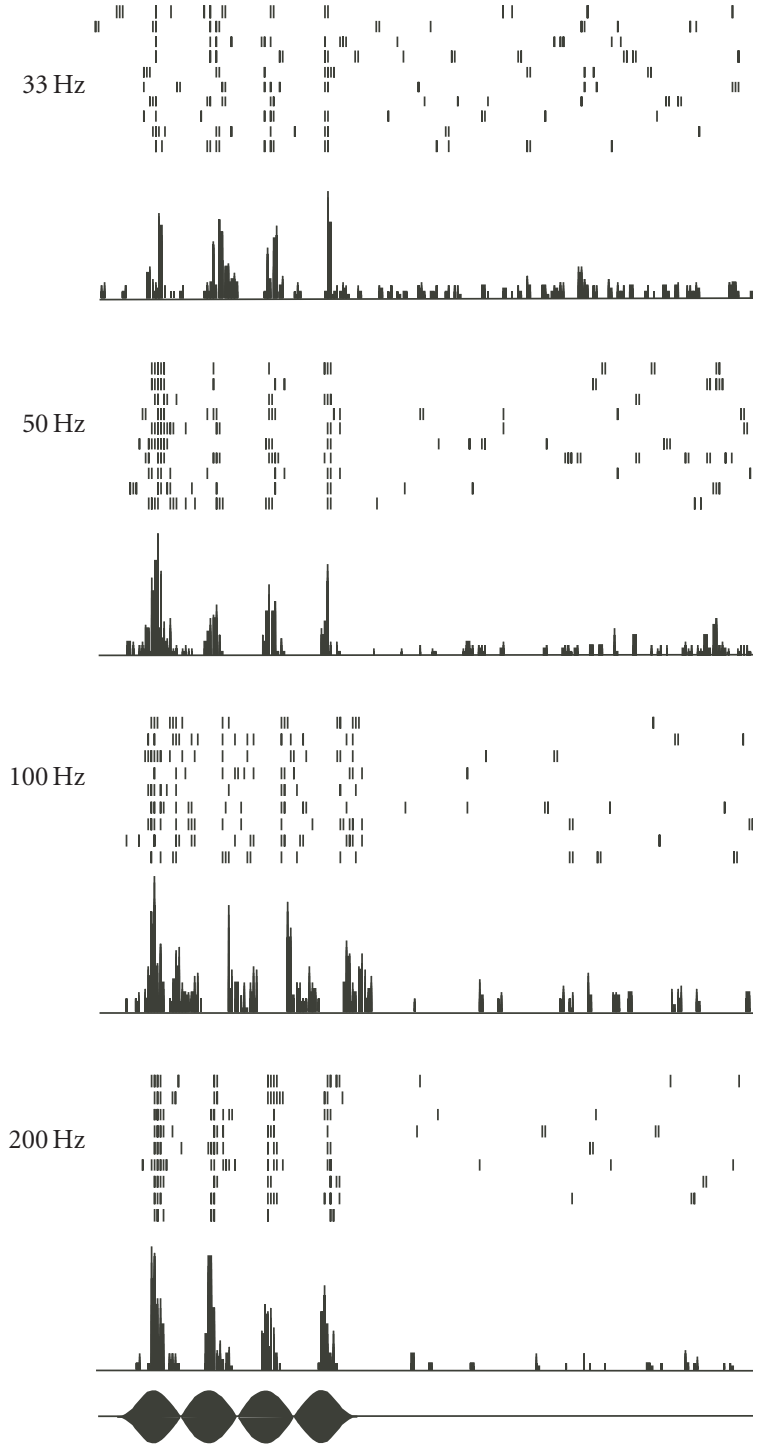

$1 \mathrm{~S}$
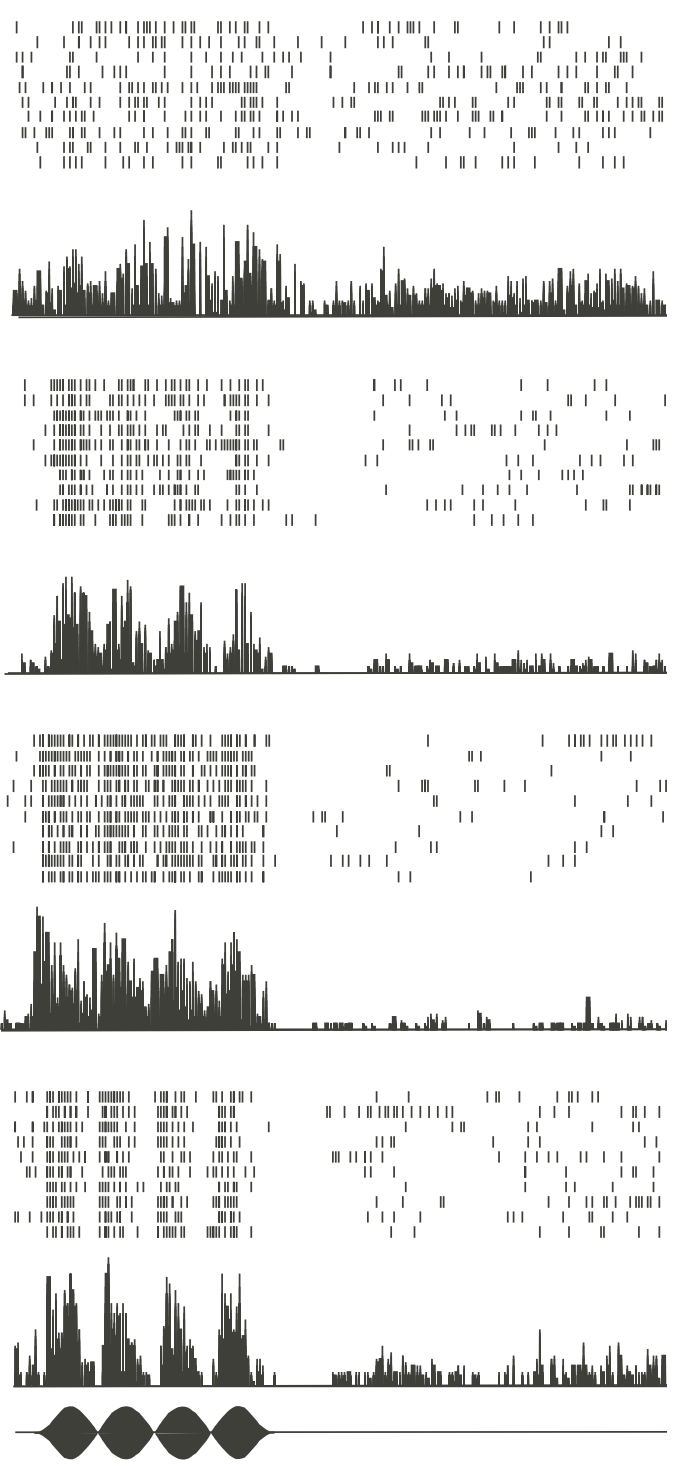

$1 \mathrm{~S}$

Figure 6: Discharge patterns of two MON units (left and right) in response to $4 \mathrm{~Hz} \mathrm{AM}$ stimuli (CF $33,50,100 \mathrm{or} 200 \mathrm{~Hz}$ ). In this and the following figure, each graph shows a dot display illustrating spike activity to ten stimulus presentations and a peri-stimulus time (PST) histogram (bin width $10 \mathrm{~ms}$ ). The envelopes of the stimulus traces are shown at the bottom. Peak-peak displacement amplitude of the sphere was $160 \mu \mathrm{m}$. Note that the units clearly phase coupled to the $4 \mathrm{~Hz}$ AM frequency.

tone stimulus of the same duration and amplitude. As in the MON, many toral lateral line units of goldfish clearly responded to the AMF, but they were not especially sensitive to AMs. In the range tested, a clear response to AM was only obtained if modulation depth was $\geq 36 \%$ [10, Table 1]. In terms of frequency response, toral lateral line units of goldfish (test range $33-200 \mathrm{~Hz})$ are low frequency $(33 \mathrm{~Hz}$ ), mid frequency $(50-100 \mathrm{~Hz})$ or high frequency $(\geq 200 \mathrm{~Hz})$. While some toral lateral line units show a broad region of about equal responsiveness that covers one or two octaves, other units are fairly narrowly tuned [10]. In summary, units in the midbrain torus semicircularis exhibit response properties to AM stimuli that are in many respects similar to those of MON units recorded in the present study (Table 1).
This implies that these properties are created first in the lateral line brainstem.

4.3. Information Processing in the Lateral Line Pathway. In the present study, responses to AM stimuli of units in the MON were found to be quite similar to those of units in the TS. In other studies, in which a moving object was used as a stimulus source, the responses of MON and TS units in many respects were also found to be very similar [38, 41, 42, 44]. Taken together, these findings at first glance suggest that only little information processing occurs between MON and TS. If this was indeed the case, then one possible interpretation would be that the difference between MON and TS is not of a qualitative but rather quantitative nature. Comparing 


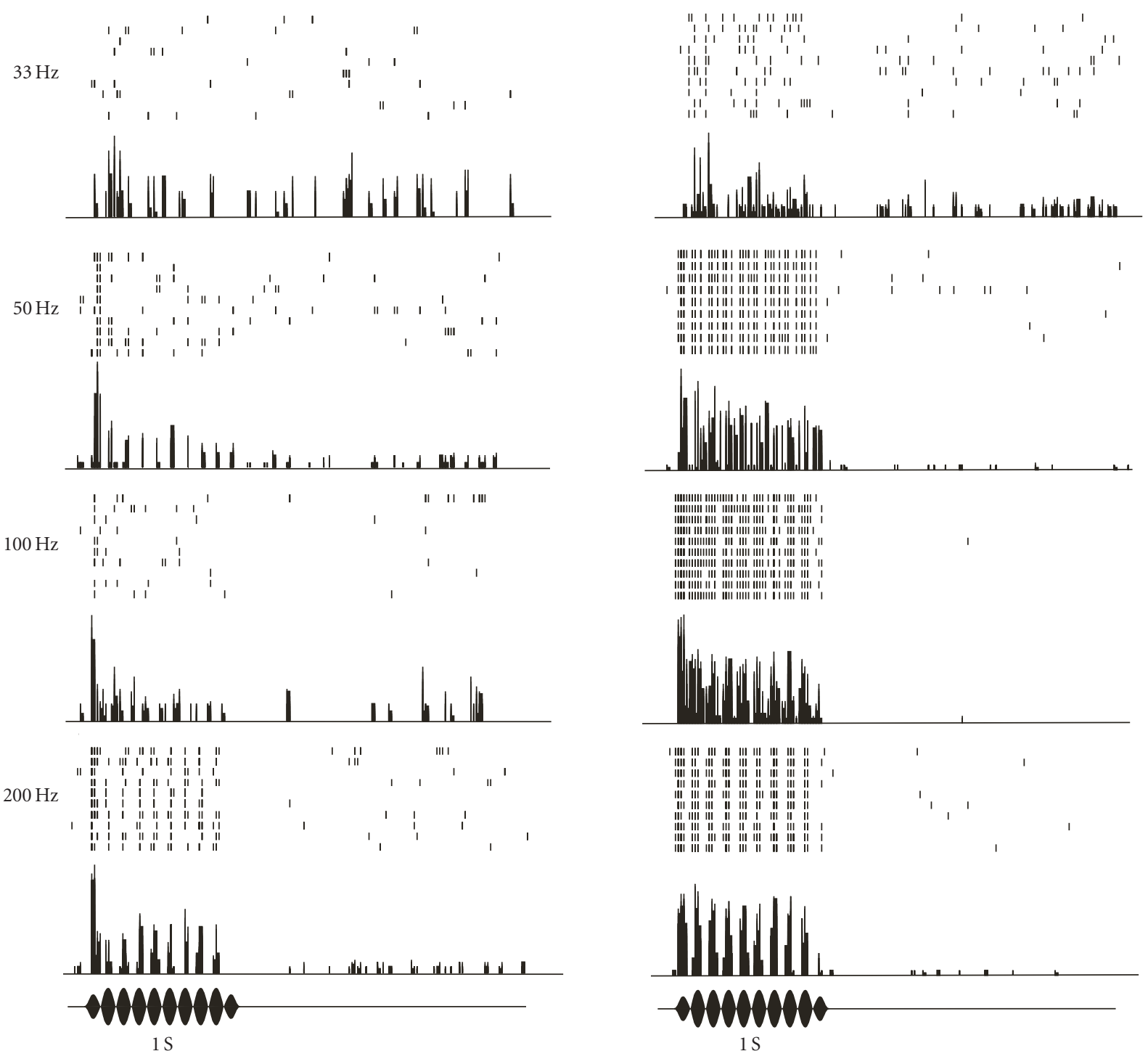

Figure 7: Discharge patterns of two MON units (left and right) in response to $10 \mathrm{~Hz}$ AM stimuli (CF $33,50,100 \mathrm{or} 200 \mathrm{~Hz}$ ). The units clearly phase coupled to the $10 \mathrm{~Hz}$ AM frequency.

TABLE 1: Comparison of the properties of the responses of lateral line nerve fibres [15], brainstem units (present study) and midbrain units [10] to constant-amplitude and amplitude-modulated sine wave stimuli.

\begin{tabular}{|c|c|c|c|}
\hline & Lateral Line Nerve & $\begin{array}{l}\text { Brainstem Medial Octavolateralis } \\
\text { Nucleus }\end{array}$ & Midbrain Torus semicircularis \\
\hline \multirow{2}{*}{ Reponse to CF } & Tonic & Phasic or tonic & Phasic \\
\hline & Strong phase locking & $\begin{array}{l}\text { Weak phase-locking to } 33 \mathrm{~Hz} \text { and } \\
200 \mathrm{~Hz} \\
\text { Strong phase-locking to } 50 \mathrm{~Hz} \text { and } \\
100 \mathrm{~Hz}\end{array}$ & Weak phase-locking \\
\hline $\begin{array}{l}\text { Response to AM } \\
\text { frequency }\end{array}$ & Strong phase-locking & $\begin{array}{l}\text { Weak phase-locking for CFs }=33 \mathrm{~Hz} \\
\text { Strong phase-locking for CFs } \geq 50 \mathrm{~Hz}\end{array}$ & Strong phase-locking \\
\hline $\begin{array}{l}\text { Effect of Modulation } \\
\text { depth }\end{array}$ & $\begin{array}{l}\text { Response reduced by only up to } \\
24 \% \text { even if } \mathrm{MD}=100 \%\end{array}$ & $\begin{array}{l}\text { Response different from response to } \\
\mathrm{CF} \text { if } \mathrm{MD} \geq 24 \% \\
\text { Lowpass }\end{array}$ & $\begin{array}{l}\text { Response different from response } \\
\text { to CF if } \mathrm{MD} \geq 36 \% \\
\text { Lowpass }\end{array}$ \\
\hline Frequency selectivity & Bandpass & $\begin{array}{l}\text { Bandpass } \\
\text { Highpass }\end{array}$ & $\begin{array}{l}\text { Bandpass } \\
\text { Highpass }\end{array}$ \\
\hline
\end{tabular}




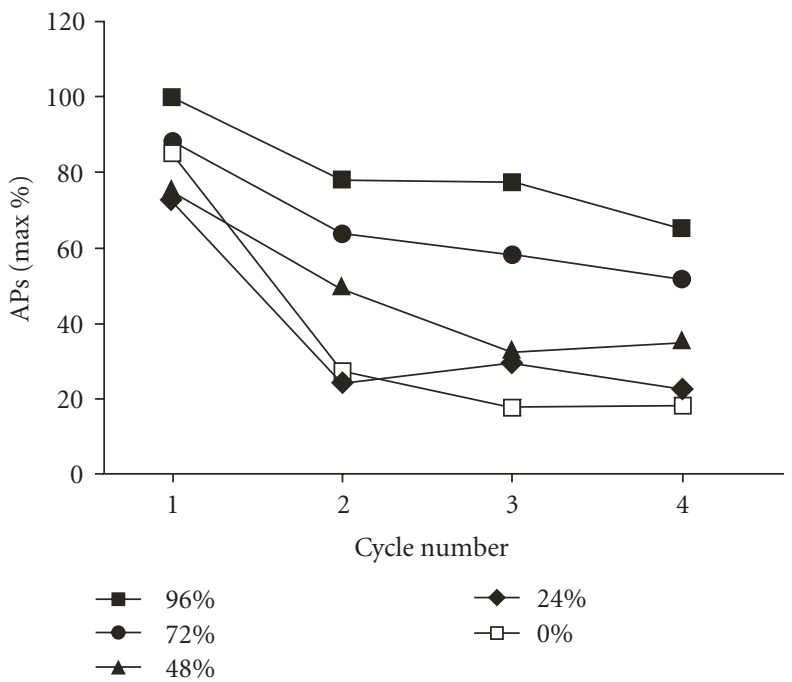

(a)

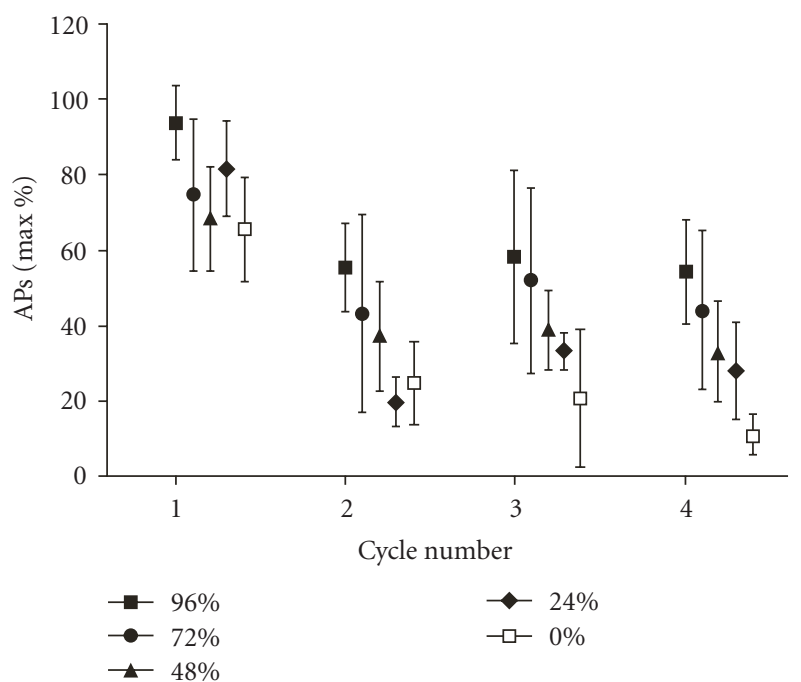

(b)

Figure 8: Effect of amplitude modulation depth on unit responses. (a) Normalized spike rate of a single unit is plotted as function of the number of AM cycles (AMF $4 \mathrm{~Hz}, \mathrm{CF} 100 \mathrm{~Hz}$ ) for different amplitude modulation depths (AMDs). (b) Normalized spike rates averaged across five MON units as function of the number of AM cycles (AMF $4 \mathrm{~Hz}, \mathrm{CF} 100 \mathrm{~Hz}$ ) at different AMDs. Vertical bars represent one standard deviation.

the present MON data with previous TS data does not suggest that this is the case. However, this question can only be resolved satisfactorily in a comparative brainstemmidbrain study. Another explanation for similarities between MON and TS responses is that some of the published TS recordings were actually made from terminals of fibers that originate from brainstem neurons. Finally, it is conceivable that the types of sensory stimuli used so far were not appropriate to work out exactly the physiological differences between MON and TS.

However, compared to other ascending sensory systems in fish, for example, the auditory or the electrosensory systems, little information processing between lateral line brainstem and midbrain would be quite unusual and other studies suggest that this is not the case. Typically, in sensory systems, there is increasing specificity and sharpening of responses to sensory stimuli, and eventually a map-like representation of the sensory environment. The fact that spontaneous rates systematically decrease from the lateral line periphery to the TS supports the notion of increasing specificity. A high spontaneous activity can be viewed as the basis for contrast enhancement because activity can be increased or decreased. This could be used by higher order neurons to respond more selectively to particular stimuli. In central neurons that are coding for distinct aspects of a sensory stimulus, a high and therefore energy-consuming spontaneous rate would not be necessary if not unwanted. Evidence for the sharpening of responses has been given by Coombs et al. [21] who showed that many MON units are spatially sharper tuned to a rowing dipole stimulus than primary afferent fibres. Finally, there is evidence for a topographic mapping of hydrodynamic information in the TS. Units that responded to an object passing anterior body areas were located in the rostral midbrain and units that responded to an object passing posterior body areas were located in the caudal midbrain. Moreover, units that responded to a passing sphere were on average located more ventrally in the lateral TS than the units that responded exclusively to a stationary vibrating sphere [45].

\subsection{Behavioral and Ecological Relevance of the Encoding of AM} Stimuli. Natural sensory stimuli contain multiple frequencies and are modulated in frequency and/or amplitude. This has been demonstrated for electrosensory (e.g., [46, 47]), auditory [48, 49] and lateral line stimuli [2, 7]. Nevertheless, pure sine waves are highly effective stimuli for the peripheral lateral line due to the biomechanical properties of the hair cells within a neuromast. As a consequence, primary lateral line afferent nerve fibres are very sensitive and respond with sustained and strongly phase-locked discharges to pure sine wave stimuli (e.g., [5, 11-15]). Central lateral line units are less sensitive, that is, they require much higher displacement amplitudes of a vibrating sphere to cause changes in discharge rate than primary afferents. Moreover, phase-coupling to pure sine wave stimuli is much weaker in central units than in primary afferents (e.g., $[8,10,20,21])$. However, as the present data show, they are sensitive for AM stimuli exhibiting sustained discharges phase-locked to the $\mathrm{AM}$ frequency. These findings indicate that the central lateral line is more adapted for the processing of natural, amplitudeand/or frequency-modulated stimuli than for the processing of pure tone stimuli that are rare or may not even occur at all in a natural environment.

This hypothesis is supported by studies on other sensory system in fish. The auditory system of goldfish, for instance, is also quite sensitive to amplitude modulations. Minimum detectable modulation depth may be as low as $0.56 \%$ [5052]. Cells showing rapid and complete adaptation to acoustic 
CF stimuli are typically the most responsive to AM signals [52]. The electrosensory system of weakly electric fish also has an impressively low threshold (Eigenmannia: $0.05 \%$ ) for AM detection [53]. These fish use their AM sensitivity for the jamming avoidance response and for electrolocation [54]. Midbrain units of catfish (Ictalurus) respond to AM sound with thresholds around 20-30\% modulation depth [55]. The data from the present study are in agreement with this finding in that MON lateral line units of Carassius were not especially sensitive to AM. A clear response to AM was only obtained if modulation depth was at least $36 \%$. A possible explanation for this finding is the fact that the AM sensitivity of Carassius should be sufficient to avoid habituation to longlasting natural hydrodynamic stimuli (e.g., [7]).

While some fish are known to react to a pure sine wave stimulus (e.g., $[11,56])$, there is only one behavioural study that tested whether fish can discriminate pure tone lateral line stimuli from amplitude-modulated lateral line stimuli. In this study it was shown that surface feeding fish do not discriminate AM water surface waves from CA single frequency wave stimuli [57]. Whether the same holds true for the lateral line system of midwater fish like the goldfish still needs to be investigated.

\section{Abbreviations}

AM: Amplitude modulation

AMD: Amplitude modulation depth

AMF: Amplitude modulation frequency

CA: Constant amplitude

CF: Carrier frequency

MD: Modulation depth

MF: Modulation frequency

MON: Medial octavolateralis nucleus

p-p: Peak-to-peak

PSTH: Peri-stimulus-time histogram.

\section{Acknowledgments}

The experiments reported in this paper comply with the current animal protection law of the Federal Republic of Germany "Tierschutzgesetz". This work was funded by a stipend of the Ministry of Higher Education in Libya to R. Ali and by the DFG (Bl-242/10-1).

\section{References}

[1] H. Bleckmann, "Role of the lateral line in fish behaviour," in The Behaviour of Teleost Fishes, T. J. Pitcher, Ed., pp. 177-202, Croom Helm, London, UK, 1986.

[2] H. Bleckmann, "Reception of hydrodynamic stimuli in aquatic and semiaquatic animals," in Progress in Zoology, W. Rathmayer, Ed., vol. 41, pp. 1-115, Fischer, Stuttgart, Germany, 1994.

[3] S. Dijkgraaf, "The functioning and significance of the lateralline organs," Biological Reviews of the Cambridge Philosophical Society, vol. 38, pp. 51-105, 1963.

[4] H. Münz, "Single unit activity in the peripheral lateral line system of the cichlid fish Sarotherodon niloticus L," Journal of Comparative Physiology A, vol. 157, no. 5, pp. 555-568, 1985.
[5] S. Coombs, M. Hastings, and J. Finneran, "Modeling and measuring lateral line excitation patterns to changing dipole source locations," Journal of Comparative Physiology A, vol. 178, no. 3, pp. 359-371, 1996.

[6] J. Engelmann, W. Hanke, and H. Bleckmann, "Lateral line reception in still- and running water," Journal of Comparative Physiology A, vol. 188, no. 7, pp. 513-526, 2002.

[7] H. Bleckmann, T. Breithaupt, R. Blickhan, and J. Tautz, "The time course and frequency content of hydrodynamic events caused by moving fish, frogs, and crustaceans," Journal of Comparative Physiology A, vol. 168, no. 6, pp. 749-757, 1991.

[8] J. Mogdans and L. Goenechea, "Responses of medullary lateral line units in the goldfish, Carassius auratus, to sinusoidal and complex wave stimuli," Zoology, vol. 102, no. 4, pp. 227-237, 1999.

[9] H. Bleckmann, O. Weiss, and T. H. Bullock, "Physiology of lateral line mechanoreceptive regions in the elasmobranch brain," Journal of Comparative Physiology A, vol. 164, no. 4, pp. 459-474, 1989.

[10] D. Plachta, J. Mogdans, and H. Bleckmann, "Responses of midbrain lateral line units of the goldfish, Carassius auratus, to constant-amplitude and amplitude-modulated water wave stimuli," Journal of Comparative Physiology A, vol. 185, no. 5, pp. 405-417, 1999.

[11] S. Coombs and J. Janssen, "Behavioral and neurophysiological assessment of lateral line sensitivity in the mottled sculpin, Cottus bairdi," Journal of Comparative Physiology A, vol. 167, no. 4, pp. 557-567, 1990.

[12] A. B. A. Kroese and N. A. M. Schellart, "Velocity- and acceleration-sensitive units in the trunk lateral line of the trout," Journal of Neurophysiology, vol. 68, no. 6, pp. 22122221, 1992.

[13] O. Sand, "The lateral line and sound reception," in Hearing and Sound Communication in Fishes, W. N. Tavolga, A. N. Popper, and R. R. Fay, Eds., pp. 459-480, Springer, Berlin, Germany, 1991.

[14] R. J. Wubbels, "Afferent response of a head canal neuromast of the ruff (Acerina cernua) lateral line," Comparative Biochemistry and Physiology A, vol. 102, no. 1, pp. 19-26, 1992.

[15] J. Mogdans and H. Bleckmann, "Peripheral lateral line responses to amplitude-modulated sinusoidal wave stimuli," Journal of Comparative Physiology A, vol. 185, no. 2, pp. 173$180,1999$.

[16] J. Engelmann, S. Kröther, J. Mogdans, and H. Bleckmann, "Responses of primary and secondary lateral line units to dipole stimuli applied under still and running water conditions," Bioacoustics, vol. 12, no. 2-3, pp. 158-160, 2002.

[17] C. A. McCormick, "Central lateral line mechanosensory pathways in bony fish," in The Mechanosensory Lateral Line. Neurobiology and Evolution, S. Coombs, P. Görner, and H. Münz, Eds., pp. 341-364, Springer, New York, NY, USA, 1989.

[18] J. G. New, S. Coombs, C. A. McCormick, and P. E. Oshel, "Cytoarchitecture of the medial octavolateralis nucleus in the goldfish, Carassius auratus," Journal of Comparative Neurology, vol. 366, no. 3, pp. 534-546, 1996.

[19] R. L. Puzdrowski, "Peripheral distribution and central projections of the lateral-line nerves in goldfish, Carassius auratus," Brain, Behavior and Evolution, vol. 34, no. 2, pp. 110-131, 1989.

[20] J. Mogdans and S. Kröther, "Brainstem lateral line responses to sinusoidal wave stimuli in the goldfish, Carassius auratus," Zoology, vol. 104, no. 2, pp. 153-166, 2001.

[21] S. Coombs, J. Mogdans, M. Halstead, and J. Montgomery, "Transformation of peripheral inputs by the first-order lateral 
line brainstem nucleus," Journal of Comparative Physiology A, vol. 182, no. 5, pp. 609-626, 1998.

[22] C. A. McCormick and D. V. Hernandez, "Connections of octaval and lateral line nuclei of the medulla in the goldfish, including the cytoarchitecture of the secondary octaval population in goldfish and catfish," Brain, Behavior and Evolution, vol. 47, no. 3, pp. 113-137, 1996.

[23] B. Oakley and R. Schafer, Experimental Neurobiology, The University of Michigan Press, Ann Arbor, Mich, USA, 1978.

[24] A. J. Kalmijn, "Hydrodynamic and acoustic field detection," in Sensory Biology of Aquatic Animals, J. Atema, R. R. Fay, A. N. Popper, and W. N. Tavolga, Eds., pp. 83-130, Springer, Berlin, Germany, 1988.

[25] G. G. Harris and W. A. van Bergeijk, "Evidence that the lateral line organ responds to near-field displacements of sound sources in water," The Journal of the Acoustical Society of America, vol. 34, pp. 1831-1841, 1962.

[26] R. M. Dowben and J. E. Rose, "A metal-filled microelectrode," Science, vol. 118, no. 3053, pp. 22-24, 1953.

[27] C. A. McCormick and M. R. Braford Jr., "Organization of inner ear endorgan projections in the goldfish, Carassius auratus," Brain, Behavior and Evolution, vol. 43, no. 4-5, pp. 189-205, 1994.

[28] J. M. Goldberg and P. B. Brown, "Response of binaural neurons of dog superior olivary complex to dichotic tonal stimuli: some physiological mechanisms of sound localization," Journal of Neurophysiology, vol. 32, no. 4, pp. 613-636, 1969.

[29] E. Batschelet, "The Rayleigh test," in Circular Statistics in Biology, E. Batschelet, Ed., pp. 54-58, Academic Press, New York, NY, USA, 1981.

[30] J. C. Montgomery, S. Coombs, R. A. Conley, and D. Bodznick, "Hindbrain sensory processing in lateral line, electrosensory, and auditory systems: a comparative overview of anatomical and functional similarities," Auditory Neuroscience, vol. 1, no. 3, pp. 207-231, 1995.

[31] B. P. Chagnaud, C. Brücker, M. H. Hofmann, and H. Bleckmann, "Measuring flow velocity and flow direction by spatial and temporal analysis of flow fluctuations," Journal of Neuroscience, vol. 28, no. 17, pp. 4479-4487, 2008.

[32] B. P. Chagnaud, H. Bleckmann, and M. H. Hofmann, "Lateral line nerve fibers do not code bulk water flow direction in turbulent flow," Zoology, vol. 111, no. 3, pp. 204-217, 2008.

[33] J. Mogdans and S. Geisen, "Responses of the goldfish head lateral line to moving objects," Journal of Comparative Physiology A, vol. 195, no. 2, pp. 151-165, 2009.

[34] J. C. Montgomery and S. Coombs, "Peripheral encoding of moving sources by the lateral line system of a sit-and-wait predator," The Journal of Experimental Biology, vol. 201, no. 1, pp. 91-102, 1998.

[35] H. Münz, "Functional organization of the lateral line periphery," in The Mechanosensory Lateral Line. Neurobiology and Evolution, S. Coombs, P. Görner, and H. Münz, Eds., pp. 285298, Springer, New York, NY, USA, 1989.

[36] M. S. Weeg and A. H. Bass, "Frequency response properties of lateral line superficial neuromasts in a vocal fish, with evidence for acoustic sensitivity," Journal of Neurophysiology, vol. 88, no. 3, pp. 1252-1262, 2002.

[37] S. Kröther, J. Mogdans, and H. Bleckmann, "Brainstem lateral line responses to sinusoidal wave stimuli in still and running water," The Journal of Experimental Biology, vol. 205, no. 10, pp. 1471-1484, 2002.

[38] J. Mogdans, H. Bleckmann, and N. Menger, "Sensitivity of central units in the goldfish, Carassius auratus, to transient hydrodynamic stimuli," Brain, Behavior and Evolution, vol. 50, no. 5, pp. 261-283, 1997.

[39] R. J. Wubbels, A. B. A. Kroese, and N. A. M. Schellart, "Response properties of lateral line and auditory units in the medulla oblongata of the rainbow trout (Oncorhynchus mykiss)," The Journal of Experimental Biology, vol. 179, pp. 7792, 1993.

[40] J. Montgomery, D. Bodznick, and M. Halstead, "Hindbrain signal processing in the lateral line system of the dwarf scorpionfish Scopeana papillosus," The Journal of Experimental Biology, vol. 199, no. 4, pp. 893-899, 1996.

[41] W. Wojtenek, J. Mogdans, and H. Bleckmann, "The responses of midbrain lateral line units of the goldfish, Carassius auratus, to objects moving in the water," Zoology, vol. 101, no. 2, pp. 69-82, 1998.

[42] H. Bleckmann and R. Zelick, "The responses of peripheral and central mechanosensory lateral line units of weakly electric fish to moving objects," Journal of Comparative Physiology A, vol. 172, no. 1, pp. 115-128, 1993.

[43] J. Engelmann and H. Bleckmann, "Coding of lateral line stimuli in the goldfish midbrain in still and running water," Zoology, vol. 107, no. 2, pp. 135-151, 2004.

[44] J. Engelmann, S. Kröther, H. Bleckmann, and J. Mogdans, "Effects of running water on lateral line responses to moving objects," Brain, Behavior and Evolution, vol. 61, no. 4, pp. 195212, 2003.

[45] D. T. T. Plachta, W. Hanke, and H. Bleckmann, "A hydrodynamic topographic map in the midbrain of goldfish Carassius auratus," The Journal of Experimental Biology, vol. 206, no. 19, pp. 3479-3486, 2003.

[46] M. E. Nelson, Z. Xu, and J. R. Payne, "Characterization and modeling of P-type electrosensory afferent responses to amplitude modulations in a wave-type electric fish," Journal of Comparative Physiology A, vol. 181, no. 5, pp. 532-544, 1997.

[47] G. von der Emde, "Electroreception," in The Physiology of Fishes, D. H. Evans, Ed., pp. 313-343, CRC Press, Boca Raton, Fla, USA, 1998.

[48] G. J. Rose and R. R. Capranica, "Processing amplitudemodulated sounds by the auditory midbrain of two species of toads: matched temporal filters," Journal of Comparative Physiology A, vol. 154, no. 2, pp. 211-219, 1984.

[49] D. A. Bodnar and A. H. Bass, "Temporal coding of concurrent acoustic signals in auditory midbrain," Journal of Neuroscience, vol. 17, no. 19, pp. 7553-7564, 1997.

[50] R. R. Fay, "Psychophysics and neurophysiology of temporal factors in hearing by the goldfish: amplitude modulation detection," Journal of Neurophysiology, vol. 44, no. 2, pp. 312332, 1980.

[51] R. R. Fay, "Neural mechanisms of an auditory temporal discrimination by the goldfish," Journal of Comparative Physiology A, vol. 147, no. 2, pp. 201-216, 1982.

[52] S. Coombs and R. R. Fay, "Adaptation effects on amplitude modulation detection: behavioral and neurophysiological assessment in the goldfish auditory system," Hearing Research, vol. 19, no. 1, pp. 57-71, 1985.

[53] G. Rose and W. Heiligenberg, "Limits of phase and amplitude sensitivity in the torus semicircularis of Eigenmannia," Journal of Comparative Physiology A, vol. 159, no. 6, pp. 813-822, 1986.

[54] W. Heiligenberg, Neural Nets in Electric Fish, MIT Press, Cambridge, Mass, USA, 1991.

[55] W. Plassmann, "Coding of amplitude-modulated tones in the central auditory system of catfish," Hearing Research, vol. 17, no. 3, pp. 209-217, 1985. 
[56] D. Hoekstra and J. Janssen, "Non-visual feeding behavior of the mottled sculpin, Cottus bairdi, in Lake Michigan," Environmental Biology of Fishes, vol. 12, no. 2, pp. 111-117, 1985.

[57] D. Vogel and H. Bleckmann, "Water wave discrimination in the surface-feeding fish Aplocheilus lineatus," Journal of Comparative Physiology A, vol. 180, no. 6, pp. 671-681, 1997. 

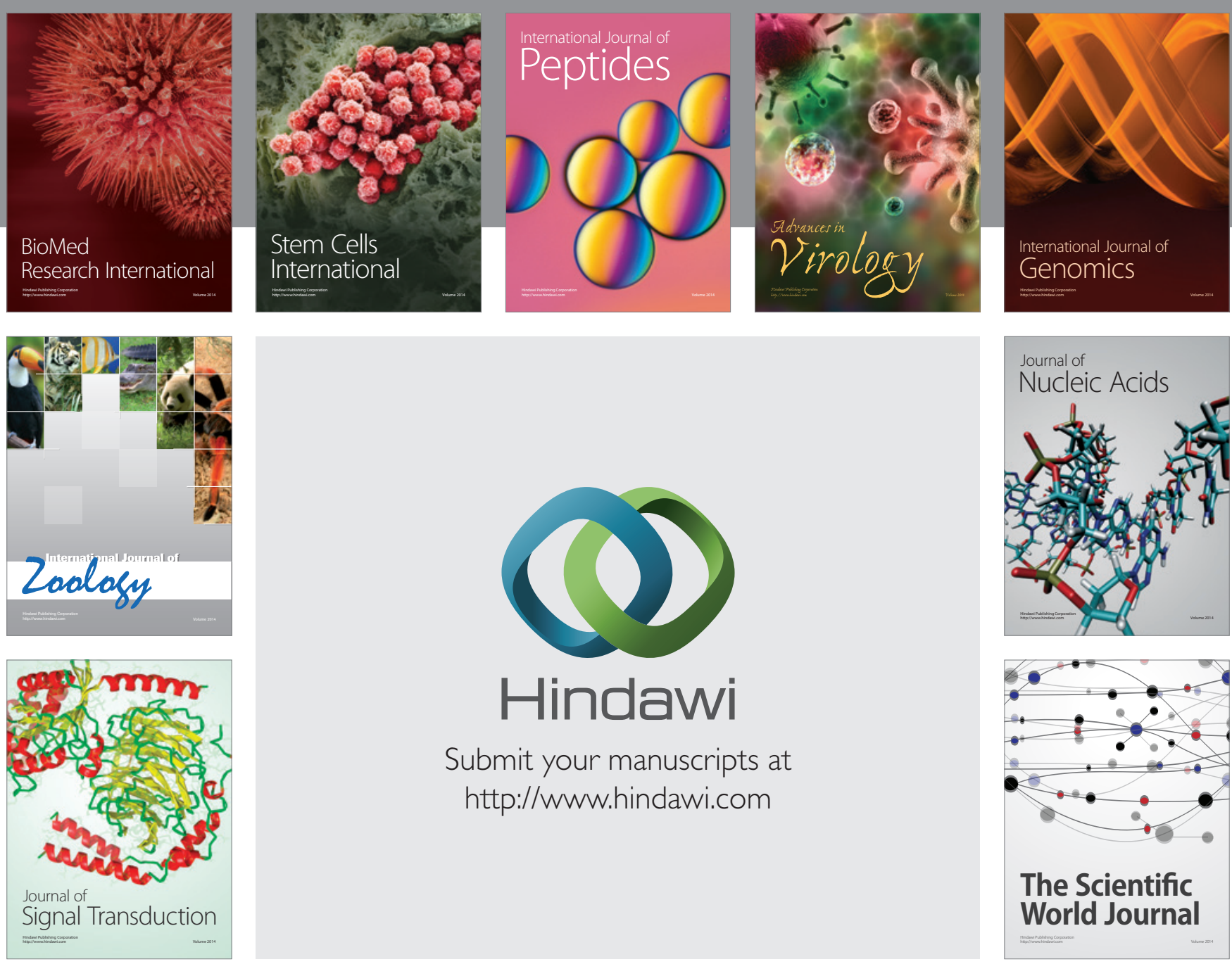

Submit your manuscripts at

http://www.hindawi.com
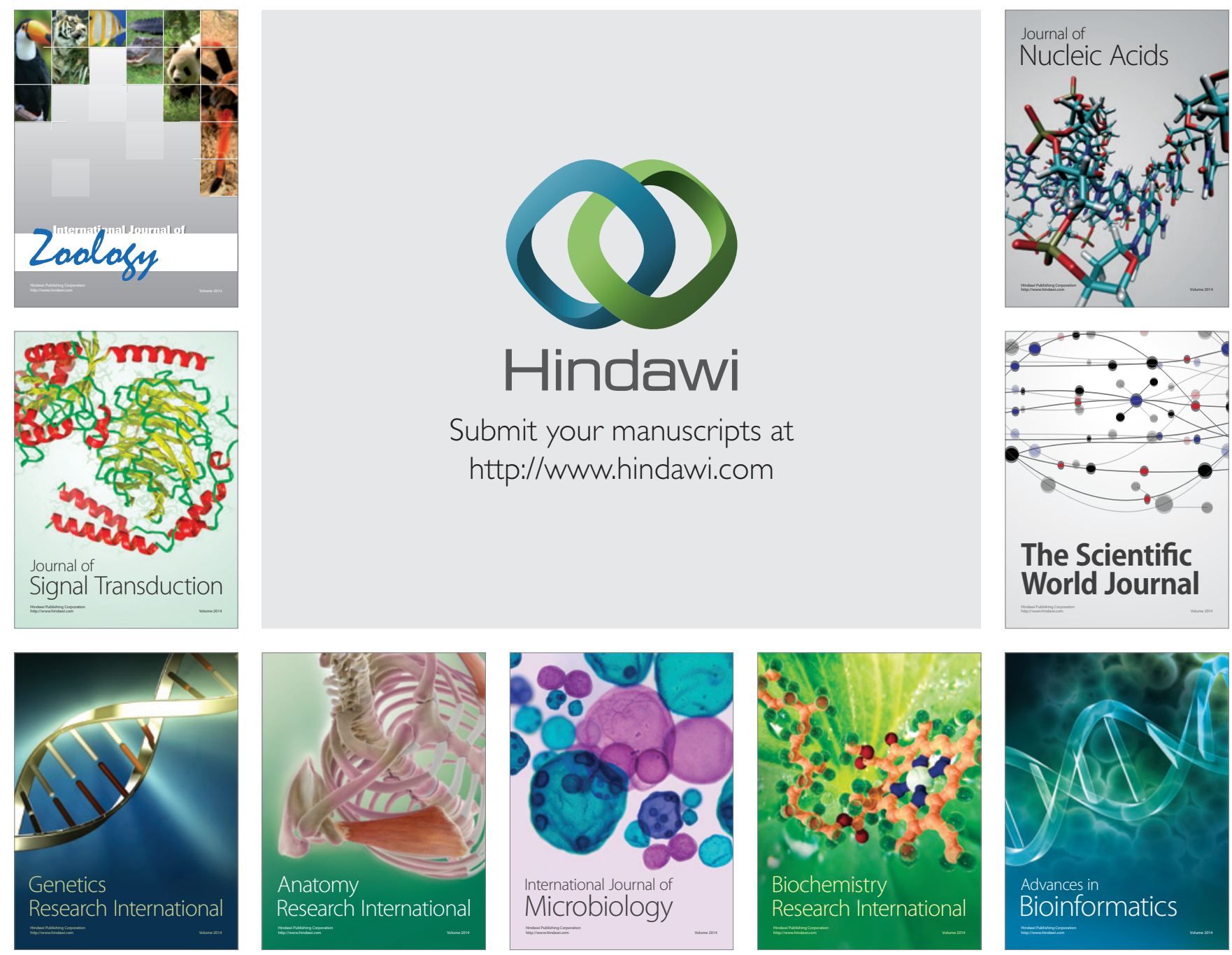

The Scientific World Journal
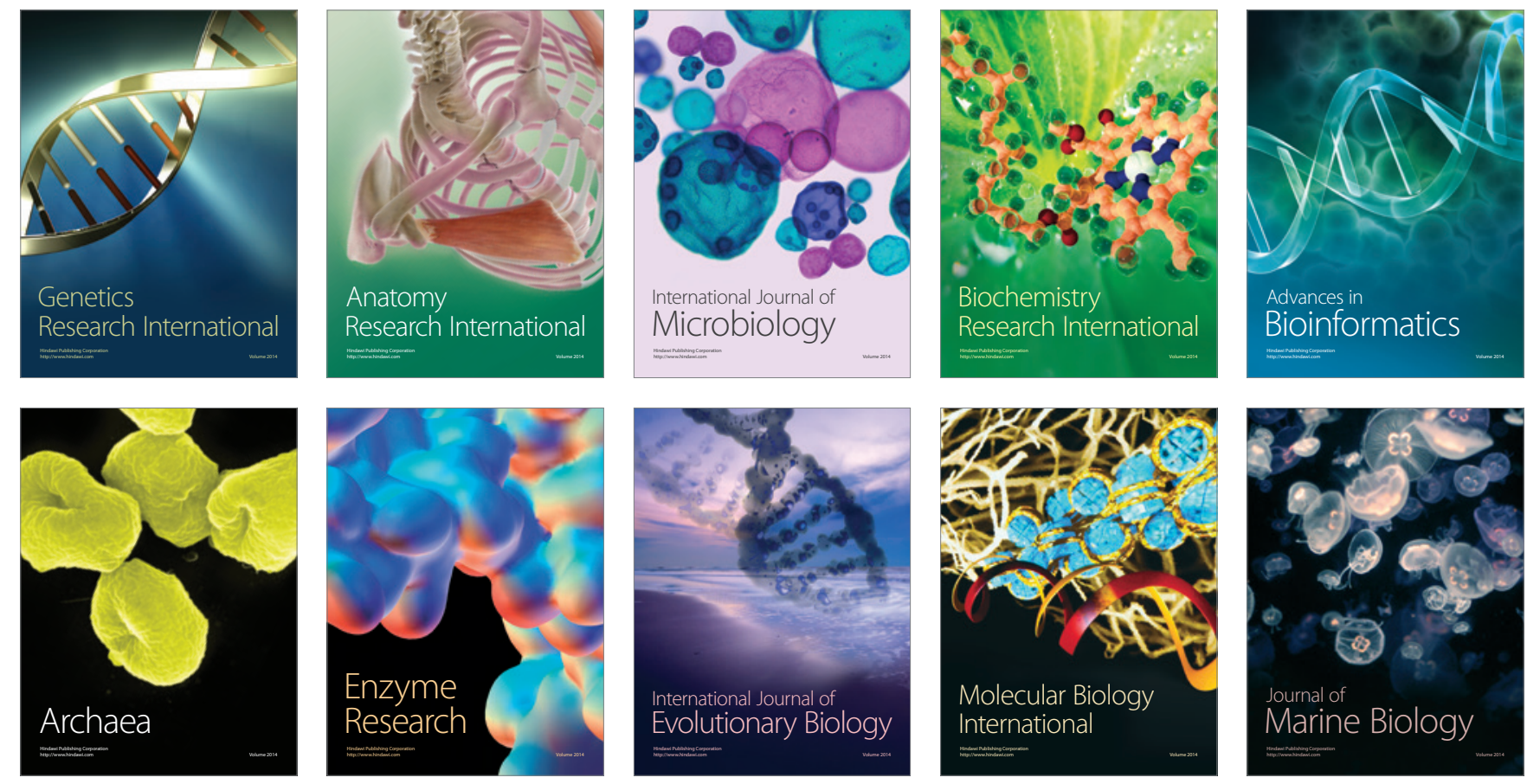